NASA/TM-2002-211313

\title{
Electric Propulsion for International Space Station Reboost: A Fresh Look
}

Steven R. Oleson and Scott W. Benson

Glenn Research Center, Cleveland, Ohio 
Since its founding, NASA has been dedicated to the advancement of aeronautics and space science. The NASA Scientific and Technical Information (STI) Program Office plays a key part in helping NASA maintain this important role.

The NASA STI Program Office is operated by Langley Research Center, the Lead Center for NASA's scientific and technical information. The NASA STI Program Office provides access to the NASA STI Database, the largest collection of aeronautical and space science STI in the world. The Program Office is also NASA's institutional mechanism for disseminating the results of its research and development activities. These results are published by NASA in the NASA STI Report Series, which includes the following report types:

- $\quad$ TECHNICAL PUBLICATION. Reports of completed research or a major significant phase of research that present the results of NASA programs and include extensive data or theoretical analysis. Includes compilations of significant scientific and technical data and information deemed to be of continuing reference value. NASA's counterpart of peerreviewed formal professional papers but has less stringent limitations on manuscript length and extent of graphic presentations.

- TECHNICAL MEMORANDUM. Scientific and technical findings that are preliminary or of specialized interest, e.g., quick release reports, working papers, and bibliographies that contain minimal annotation. Does not contain extensive analysis.

- CONTRACTOR REPORT. Scientific and technical findings by NASA-sponsored contractors and grantees.
- CONFERENCE PUBLICATION. Collected papers from scientific and technical conferences, symposia, seminars, or other meetings sponsored or cosponsored by NASA.

- SPECIAL PUBLICATION. Scientific, technical, or historical information from NASA programs, projects, and missions, often concerned with subjects having substantial public interest.

- TECHNICAL TRANSLATION. Englishlanguage translations of foreign scientific and technical material pertinent to NASA's mission.

Specialized services that complement the STI Program Office's diverse offerings include creating custom thesauri, building customized data bases, organizing and publishing research results ... even providing videos.

For more information about the NASA STI Program Office, see the following:

- Access the NASA STI Program Home Page at http://www.sti.nasa.gov

- E-mail your question via the Internet to help@sti.nasa.gov

- Fax your question to the NASA Access Help Desk at 301-621-0134

- Telephone the NASA Access Help Desk at 301-621-0390

- Write to:

NASA Access Help Desk

NASA Center for AeroSpace Information 7121 Standard Drive

Hanover, MD 21076 
NASA/TM-2002-211313

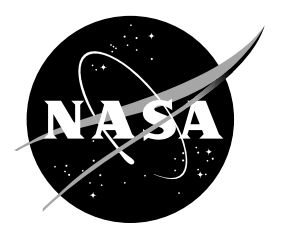

\section{Electric Propulsion for International Space Station Reboost: A Fresh Look}

Steven R. Oleson and Scott W. Benson

Glenn Research Center, Cleveland, Ohio

Prepared for the

37th Joint Propulsion Conference and Exhibit

cosponsored by the AIAA, SAE, AIChE, and ASME

Salt Lake City, Utah, July 8-11, 2001

National Aeronautics and

Space Administration

Glenn Research Center 


\section{Acknowledgments}

The authors wish to recognize the NASA Glenn Research Center and the Marshall Space Flight Center teams for their creative and thorough work on the ISS electric propulsion study, some of which is included in this report.

We wish to especially recognize the support of Rob Alexander and Bill Spetch of Johnson Space Center for
supplying many of the ISS unique requirements without which this study could not have been completed.

We wish to especially recognize the support of Rob Alexander and Bill Spetch of Johnson Space Center for
supplying many of the ISS unique requirements without which this study could not have been completed.

This report contains preliminary findings, subject to revision as analysis proceeds.$$
\text { raralo }
$$

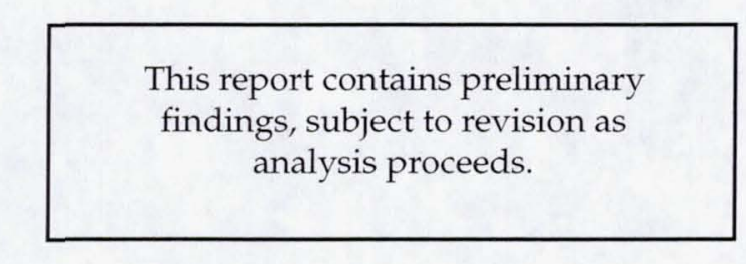

\footnotetext{
NASA Center for Aerospace Information 7121 Standard Drive

Hanover, MD 21076
} National Technical Information Service
5285 Port Royal Road
Springfield, VA 22100

Available from 


\title{
Electric Propulsion for International Space Station Reboost: A Fresh Look
}

\author{
Steven R. Oleson and Scott W. Benson \\ National Aeronautics and Space Administration \\ Glenn Research Center \\ Cleveland, Ohio 44135
}

\begin{abstract}
Electric propulsion has recently been revisited for reboost of space station due to its high fuel efficiency. This paper focuses upon the propulsion system and orbit analysis trades undertaken at the beginning of a study to show the relative performance of potential electric propulsion system. A code was developed to analyze continuous low thrust reboost of space station with various electric propulsion systems at various power levels. Analysis showed that a major portion of reboost of space station can be made using electric propulsion systems with $0.5 \mathrm{~N}$ of continuous thrust. $1.0 \mathrm{~N}$ of EP thrust can provide almost the entire reboost mission. Three electric propulsion systems at various total power levels were chosen for further investigation: $\mathrm{N} 2 \mathrm{H} 4$ arcjets at $5 \mathrm{~kW}$, xenon Hall at $10 \mathrm{~kW}$, and xenon ion thrusters at $20 \mathrm{~kW}$. They were chosen for their ability to reduce the internationally launched chemical reboost fuel by $50 \%$ or more.
\end{abstract}

\section{Introduction}

Electric propulsion has been explored in the past for reboost of space station. ${ }^{1,2,3,4}$ These past studies mainly focussed on using space station waste gases as propellants in order to reduce the amount of reboost fuel needed to offset atmospheric drag and keep the station in its proper orbit. Results of these studies showed large savings in terms of launched chemical reboost fuel. However, the complexity and safety issues of tying the electric propulsion system into the waste gas systems were considered too great and electric propulsion was not implemented.

With the advent of high efficiency, operational electric propulsion systems such as arcjets, Hall, and gridded ion systems, as well as newly emerging electric propulsion technologies, a new look at using electric propulsion for reboost of International Space Station (ISS) was deemed necessary. This study was performed jointly between Glenn Research Center (GRC) and Marshall Space Flight Center (MSFC) with support from other NASA centers such as Johnson Space Center (JSC).

Use of these electric propulsion technologies usually required propellants not native to ISS (e.g. hydrazine and xenon), so the issues of tying the EP system into an existing waste gas system could be avoided. However, these EP technologies require higher power levels than the waste gas resistojets considered in past studies and the issues of adding power to the space station had to be included.

This study had two parts, the first to determine the relative benefits of each electric propulsion device and a second to do a preliminary engineering concept definition of selected devices from the first study phase. With the second phase yet to be completed at the time of this writing only the first phase showing the analysis for downselect is shown. In the first phase a model was created to compare each electric propulsion system's performance for the reboost mission over a tenyear period. The reboost mission was defined from current space station plans and estimates of altitude and atmospheric drag. Downselect of technologies for the second phase was made on the basis of chemical reboost fuel saved, technology readiness level, and power level required for electric propulsion. While the use of electric propulsion on space station can have other benefits such as microgravity environment enhancement and space station charge control, only the benefit of reduction in chemical reboost fuel was considered in this work. 


\section{Baseline Chemical Reboost Mission}

The current chemical propulsion systems used on ISS perform more than just reboost. These other functions include attitude control, and collision avoidance. Due to the high thrust levels, integration challenges, and relatively low fuel requirements, none of these other functions was considered for an EP system.

The reboost mission itself is not merely a fixed orbit band where the reboost system lifts the ISS back to the top of the orbit band after it drags down to the bottom of the orbit band. Due to the variation in atmospheric drag from the 11-year solar cycle, the ISS needs to be lifted approximately $100 \mathrm{~km}$ to a higher orbit $(460 \mathrm{~km})$ during solar maximum in order to minimize the drag force. JSC defines an ISS altitude strategy during Design Analysis Cycle (DAC) activities. The DAC 8 strategy, illustrated in Figure 1 was the reference for this study. When the solar cycle returns to its minimum the ISS orbit is allowed to fall back to a lower orbit $(\sim 360 \mathrm{~km})$. (While the station could maintain a $460 \mathrm{~km}$ orbit regardless of year this would greatly reduce the delivered payload mass capabilities for the ISS logistics carriers, namely, Space Shuttle, Progress, Soyuz, and the European and Japanese Transfer Vehicles.) In addition, the ISS is required to stay above two varying altitudes during its mission: the 180 day no thrust orbit life altitude (the orbit at which the re-entry of ISS is predicted to take 180 days) and the minimum micro-g altitude to ensure proper micro-gravity for ISS experiments. These altitude lines are shown in Figure 1.

The actual orbit that the ISS is planned to fly is also shown in Figure 1 as a sawtooth line. With the chemical system the ISS is boosted to a higher orbit and the drag brings the ISS down to the microgravity environment limit altitude.

The ISS must violate the microgravity and 180 day life altitudes during the solar maximum portion of the mission, also shown by Figure 1 . The chemical upper orbit is limited to $460 \mathrm{~km}$ due to ISS design constraints. The ISS must also descend to $423 \mathrm{~km}$ roughly every six months to rendezvous with a Soyuz. This rendezvous is extremely important since the Soyuz performs the role of a lifeboat for ISS at assembly complete and the on-orbit lifetime for the Soyuz is limited to six months. This descent to $423 \mathrm{~km}$ places the ISS in a very high drag situation, which shall be shown later to limit the amount of EP that can be used for the ISS mission.

The data shown in Figure 1 from JSC was used as the basis for the EP analysis. It assumed a most likely atmospheric density variation over the ten-year period under investigation. The ten-year period was chosen to begin in 2006 and end in 2016. While the design life of the ISS exceeds this date, this 10 -year period was used to show EP's advantage over a nearly complete solar cycle. The impacts and limitations of EP for subsequent solar cycles would be similar.

The data from JSC also included most events over the life of the ISS including service spacecraft dockings/undockings and of course chemical reboost events. The actual decay of ISS was calculated elsewhere and included in the data along with the ISS mass, atmospheric density, and ballistic number or coefficient $(\mathrm{BN}=$ Mass $/$ (Coefficient of Drag * CrossSectional area)). The ballistic number was set at a constant $\left(86.5 \mathrm{~kg} / \mathrm{m}^{2}\right)$ over the reboost mission. The station is assumed complete in this analysis so the mass (469687 $\mathrm{kg}$ ) was assumed constant. While the ISS mass does vary due to dockings/undockings and fuel use this variation was NOT considered in the calculation of fuel mass due to is minimal impact on the total mass of station. The crosssectional area was assumed to be an average $2300 \mathrm{~m}^{2}$ so the coefficient of drag was determined to be 2.35 from the ballistic number. As with the space station mass the cross-sectional area and coefficient of drag are assumed fixed for the baseline analyses.

The chemical reboosts assumed simple twoburn Hohmann transfers which defined the required chemical $\Delta \mathrm{V}$. The chemical propulsion system Isp was assumed to be 300 seconds based on the existing ISS bi-propellant chemical propulsion systems used for reboosts.

\section{Electric Propulsion Reboost Mission Analysis: Approach and Assumptions} In order to assess the use of EP for the ISS reboost mission a low thrust code was written around the data provided by JSC. The amount of orbit raised or lowered during a coast or an EP burn was assessed by a simple routine which added the drag force $(-)$ and the EP thrust force $(+)$ to give a net force $(+$ or - ). This net force was then used to assess the 
amount of orbit raise or decay for each orbit. This approach has been used successfully in past analyses and is accurate enough for scoping analyses such as this one. ${ }^{5,6}$

The code allows for either no shadow or maximum shadowing and a variation in the spacecraft, thrust and drag inputs. The spacecraft inputs are similar to those used in the JSC baseline chemical analysis given in the last section: mass, coefficient of drag, and cross-sectional area. If the EP system requires dedicated solar power this cross-sectional area is halved (for a rough average) and added to the space station average cross-sectional area. The thrust is calculated from the EP system attributes, namely power, total efficiency, Isp. The drag force is calculated by the simple equation:

Drag force $=-1 / 2 *$ Density $*$ Drag Coefficient

* Area * Satellite Velocity ${ }^{2}$

The ISS velocity is dependent upon the assumed circular altitude. As with the JSC analysis, the ISS orbit is assumed (and calculated) to be circular. The atmospheric density given in the JSC analysis was specific to the assumed ISS altitude and date. The atmospheric density varies based on complex solar flux models. In order to use the JSC data and not rely on an external program to recalculate the atmospheric density a linear fit to the JSC atmospheric data was used. When the reboost mission was calculated using the code for the chemical reboosts only, the results were within $5 \%$ of the baseline JSC case.

Logic was written into the code to keep the ISS altitude as near the microgravity line of the JSC baseline as close as possible. In some cases a chemical boost was still required even though EP was present since the thrust force of the EP system was less than the drag. This was especially true when the ISS descended to rendezvous with a Soyuz spacecraft as discussed earlier. Figure 2 shows the drag force on ISS over the ten-year period. The higher drag forces are clearly centered on the solar max of 2012. In some cases the EP system would have too much thrust and would be shut off to prevent the ISS from gaining too much altitude.
Considering this variation in drag three applications of EP are possible. At very low $\mathrm{EP}$ thrust levels $<0.2 \mathrm{~N}$, termed here as 'parachute mode' no orbit raising is possible so the EP system will just offset some of the drag and the chemical system will perform the reboosts, just not as often. At higher thrust levels, around $0.5 \mathrm{~N}$, EP can perform a good portion of the reboost mission, except for most of the $100-\mathrm{km}$ orbit raise and the reboosts after descent to rendezvous with the Soyuz during solar max. This mode is termed 'partial primary'. Finally, at high EP thrust levels, about $1.5 \mathrm{~N}, \mathrm{EP}$ can handle the entire reboost mission, replacing the chemical reboosts entirely. This last mode is termed 'primary' and usually requires large amounts of power for very little additional chemical fuel savings.

Sample altitude histories using the parachute and partial primary EP options are shown in Figures 3 and 4, respectively. The baseline chemical reboosts are also shown. Figure 3 shows a parachute mode using one, $5 \mathrm{~kW}$ Hall thruster. The thruster is operated continuously and only offsets some of the drag. Figure 4 shows two simultaneously operating $2.5 \mathrm{~kW}$ arcjets. It is clear from the figure that the only chemical reboosts needed are to assist in the $100-\mathrm{km}$ orbit raise (2008 to 2010) and for reboost after Soyuz dockings. Note also that the use of EP slows orbital decay and allows a lower peak altitude $(450 \mathrm{~km}$ instead of $460 \mathrm{~km}$ ) which saves chemical propellant.

\section{EP System Options and Assumptions}

In order to capture as many possible EP solutions the trade space was opened not only to off-the-shelf EP devices but also those under development. It was reasoned that if an immature EP technology was found to be advantageous to ISS reboost its development could be accelerated.

Electric propulsion is normally broken up into three sub-categories: electrothermal, electrostatic, and electromagnetic. Each of the EP candidates will be discussed within its subcategory. A complete listing of the EP candidates and their attributes is given in Table 1. The important attributes included those of performance (Isp, efficiency, input power, lifetime) and subsystem masses. 


\section{Electrothermal}

Three device types currently exist which use electrical power to thermally heat a propellant and subsequently expand it out a nozzle to provide thrust: resistojets, arcjets, and microwave electrothermal thrusters.

The simplest of these is the resistojet, which uses a resistively heated wire to heat the propellant. Performance of these devices is normally poor $(<300 \mathrm{~s})$ compared to other EP devices but can be advantageous from the standpoint of low power requirements and if free propellant is available. For ISS, many potential some gases/liquids exist, such as $\mathrm{CO}_{2}, \mathrm{CH}_{4}, \mathrm{~N}_{2}, \mathrm{H}_{2} \mathrm{O}$. Earlier studies utilized these waste gases to great effect. One resistojet developed to use these waste gases, was developed at Glenn Research Center. ${ }^{2}$ In the current ISS infrastructure water is not considered available for propulsion. Only $\mathrm{CO}_{2}$ was considered in this study for a resistojet. The $\mathrm{CO}_{2}$ production was estimated based on the nominal astronaut crew of seven. This limit, in turn, sets the continuous thrust level of the resistojet.

Better Isp performance (500 to 1000 seconds) is available with an arcjet. The higher temperature in the arc allows this improved performance. Two options were considered in this study: hydrazine arcjets which are operational on geosynchronous spacecraft and an ammonia arcjet which was flight tested on the ESEX spacecraft. ${ }^{7,8}$ While hydrogen arcjets have been developed as lab devices, launch of a significant quantity of hydrogen propellant on STS was considered impractical. ${ }^{9}$ Both a $2.5 \mathrm{~kW}$ hydrazine arcjet and a pulsed $30 \mathrm{~kW}$ ammonia arcjet were considered for the ISS reboost mission.

The microwave electrothermal thruster (MET) which utilizes a microwave source to heat a propellant has been developed by Micci and others at Penn State University. ${ }^{10}$ The thruster which promises a specific impulse of 460 seconds or higher using a water propellant, and high total efficiencies (over 40\%) with water has yet to verified.

\section{Electrostatic}

Three device types currently exist which use electrical power to ionize a propellant and then accelerate it through an electrostatic field to provide thrust: ion thrusters, Hall thrusters, and colloid thrusters.
Invented by Kaufman in the 1960's the gridded ion thruster (hereafter called 'ion thruster') has experienced great success in the last decade. Successes such as the flight of the NSTAR $2.5 \mathrm{~kW}$ ion thruster on the Deep Space 1 mission as well as the commercial flights of the Boeing 601 and 702 ion thrusters (formerly the Hughes XIPS 13 and XIPS 25) has established this technology as operational. ${ }^{11}$ The NSTAR device has demonstrated high Isps (>3000s) and long lifetimes $(>12,000$ hours). The $2.5 \mathrm{~kW}$ NSTAR thruster was chosen as representative for the ISS application.

Also invented in the 1960's and perfected in Russia, the Hall effect thruster has also been flown on many Russian geosynchronous spacecraft as well as the US research spacecraft STEX. ${ }^{12}$ Compared to the ion thruster the Hall provides a lower Isp ( ranging from $1200 \mathrm{sec}$ to $3000 \mathrm{sec}$ ) but still long lifetimes ( $>7000 \mathrm{hrs})$. In many mission trades for earth orbit applications the Hall thruster has been shown to outperform the ion thruster due to a better operating Isp/thrust range. ${ }^{13}$ Hall thrusters exist in many power levels ( $50 \mathrm{~W}$ to $50 \mathrm{~kW}$ ), whether in operational or laboratory form. For the ISS study a $5 \mathrm{~kW}$ Hall thruster (several of which are commercially available and near flight) was assumed. ${ }^{14}$

The colloid electrostatic thruster exists in laboratory form and as the FEEP (Field Effect Electric Propulsion) thruster. These devices are very low power (watts) and are not considered for reboost of the large ISS.

\section{Electromagnetic}

Three device types currently exist which use electrical power to ionize a propellant and accelerate it with a magnetic field to provide thrust.

Magnetoplasmadynamic (MPD) thrusters operate with an induced magnetic field created from an arc, very similar to arcjets but at lower flow rates, such that the major acceleration force on the propellant is from the magnetic field and not from the thermal heating of the propellant as with the arcjet. ${ }^{15}$ Pulsed Inductive thrusters induce a repulsive acceleration from an electromagnetic pulse. ${ }^{16}$ The VASIMR thruster system operates as three stages: ionization, rotational acceleration, and a magnetic nozzle for conversion to translational thrust. ${ }^{17} \quad$ All of these devices 
exist in laboratory form and provide high Isps (3000 $\mathrm{sec}$ to $10,000 \mathrm{sec}$ ) and normally require high powers $(>100 \mathrm{~kW})$ to be efficient. The VASIMR was chosen as representative for this class of devices since $10 \mathrm{~kW}$ VASIMR preliminary designs have been made.

\begin{abstract}
Power
Except for the resistojet, the EP devices being considered will require substantial power levels ( $2 \mathrm{~kW}$ to $30 \mathrm{~kW}$ ) which may or may not be available from ISS. An assumption was made that ISS would make a continuous $6 \mathrm{~kW}$ available for EP operations. $1 \mathrm{~kW}$ of this $6 \mathrm{~kW}$ was reserved for EP system auxiliary power requirements such as thermal and control, so only $5 \mathrm{~kW}$ of power was assumed for the production of thrust. If more power was needed a power system was added to the ISS to provide all of it; no mixing of ISS and EP power was considered. The dedicated, continuous EP power was added to ISS at a rate of $100 \mathrm{~kg} / \mathrm{kW}$ and an averaged crosssectional area of $244 \mathrm{~W} / \mathrm{m}^{2}$. This system included batteries for powering the EP system during shadow conditions. Cost of the added system was considered in the second phase of the study and is not addressed here. In all cases the EP system was run continuously, unless the EP system provided too much thrust, at which point is was cycled to maintain proper orbit.
\end{abstract}

\begin{abstract}
Analysis
Each EP system was run with sufficient power for each of the three operational modes: parachute, partial primary, and primary. The amount of EP $\Delta \mathrm{V}$ versus the EP thrust level is approximately independent of EP type as shown by Figure 5 .
\end{abstract}

\section{Results and Discussion}

Down-selection of the most attractive systems for further study was based upon several figures of merit. The selectors were chemical fuel mass savings and technology readiness level. Secondary selection considerations included electric propulsion fuel mass, EP system dry mass, and required number of thrusters. Each figure of merit will be treated separately.

\section{Chemical Fuel Mass Savings}

By varying the power level with each EP system, Figure 6 was made to show the chemical fuel savings versus EP power level. This reduction in chemical fuel mass would reduce the reliance on international reboost flights (Progress, European transfer vehicle). The figure ignores the required EP fuel and system mass and only shows the international chemical fuel required. It should be noted here that reduction in reboost fuel requirements would allow more dry cargo (consumables, science instruments, and commercial equipment) to be launched to space station. The amount of international fuel saved is only dependant upon the thrust available from the EP device.

The waste gas $\mathrm{CO}_{2}$ thruster's power was limited by the amount of $\mathrm{CO}_{2}$ available, thus the savings was negligible. Both the MET and the $\mathrm{N}_{2} \mathrm{H}_{4}$ arcjet can reduce the required chemical fuel by more than half using the $5 \mathrm{~kW}$ assumed available space station power. At $10 \mathrm{~kW}$ the arcjet and Hall thruster systems provide even more benefits with the arcjet providing almost the whole reboost mission. Note that the Hall thruster provides roughly the same chemical fuel savings at the $10 \mathrm{~kW}$ power point as the arcjet at the $5 \mathrm{~kW}$ power point.

Each EP system reboost performance peaks when the power is sufficient enough to provide most of the reboost mission. Thus the higher the Isp of the EP system the more power required to provide sufficient thrust.

\section{Electric Propulsion Fuel Requirements}

The electric propulsion fuel required to offset the chemical fuel in Figure 6 is shown in Figure 7 verses power level. Due to its lower Isp the MET system requires around $45 \mathrm{MT}$ (Metric Tons) of water to replace all but 5 MT of the chemical propellant. Currently, space station is planning to use the excess water to produce oxygen so the water would have to be brought up with shuttle.

The $\mathrm{N}_{2} \mathrm{H}_{4}$ arcjet system requires fuel loading in the $25 \mathrm{MT}$ to $35 \mathrm{MT}$ range to provide $42 \mathrm{MT}$ to 62MT chemical fuel savings. The Hall and ion systems require around $10 \mathrm{MT}$ and $5 \mathrm{MT}$ of fuel respectively, for similar substantial chemical fuel savings. The VASIMR with its very high Isp requires very little propellant $(<5$ MT $)$ but saves very little chemical propellant unless $30 \mathrm{~kW}$ of continuous power can be added.

\section{Required EP and Chemical Fuel Mass}

The fuel required for the EP system (along with the system itself) is assumed to be shuttle 
launched. Figure 8 shows the amount of EP fuel required along with the international chemical fuel required. In terms of the required fuel a number of the EP systems provide similar results at the $5 \mathrm{~kW}$ power level point, a level assumed to be available from ISS for reboost. The required amount of total reboost fuel is reduced by about 20MT out of $65 \mathrm{MT}$ for several of the systems including the Hall and arcjet. Increasing power to $10 \mathrm{~kW}$ reduced the total fuel requirements to about 25 MT with Hall thrusters. Going to higher powers allows even more up fuel mass reduction though at a lesser rate. Over the 5 to $20 \mathrm{~kW}$ range the Hall thruster option requires the least amount of total chemical and electric reboost fuel.

\section{Power Level}

Such comparisons of chemical fuel mass saved and EP fuel required ignore several other potentially massive and expensive items namely the added power system, the EP system itself and the integration mass to launch the EP system (and added power system) on the Shuttle and attach it to ISS. While these masses, especially the integration mass, can not be assessed until the second phase of the study, it must be stressed here that the attractiveness of the higher Isp systems (Hall, Ion, and VASIMR) must be tempered somewhat by the potential for heavy and expensive integration and power systems. Alternatively, ISS may choose to provide the necessary power portion to the EP system if it deems the reduction of internationally launched chemical fuel warrants it.

\section{Technology Readiness Level}

With a 2007 start of operations date for the EP system it was deemed that a technology readiness level must be high enough to allow for integration into the ISS as a primary flight system. An EP technology freeze date of 2004 was selected. As such it was decided that candidate technologies with very low TRL levels (MET and VASIMR) would not be considered for application to ISS in 2007.

\section{Required Number of Thrusters}

As a test of each EP system's ability to perform the mission, the number of thrusters required due to operational power level and lifetime limitations was calculated. Since the EP system will be operating most of the mission, (as many as ten years or more), as much as 87 thousand hours of operation is required. Figure 9 shows the required number of thrusters for each concept. Some of the concepts are not included since lifetime is not known.

The $\mathrm{CO}_{2}$ resistojet has completed a lifetest of 10,000 hours so less than 10 would be needed. Almost ninety $2.5 \mathrm{~kW}$ arcjets are required at the $5 \mathrm{~kW}$ level. This 90 thruster approach will require a more complex power processing, control, and feed system, but each thruster is light, small, and simple. Increasing lifetime and power level of the arcjet system is being considered in the second phase analysis with a development program. A $5 \mathrm{~kW}$ arcjet with 2500 hours of life would bring the number of arcjets down below 40 .

The Hall system is appropriately powered at $5 \mathrm{~kW}$ for a dual operating $10 \mathrm{~kW}$ system. Even with a lifetime of 8000 hours, 20 thrusters are required to complete the mission. If 8000 thousand-hour lifetime, $10 \mathrm{~kW}$ Hall thrusters were used to provide thrust (an engineering model has completed 1000 hours of test) this number could be halved. ${ }^{18}$

Although the NSTAR ion thruster has a longer life than the Hall thruster, the lower power level of the device $(2.5 \mathrm{~kW})$ and the higher ISS application power of $20 \mathrm{~kW}$ would require 30 or more thrusters for the reboost applications of interest. This number could be reduced by using the Boeing 702 thruster $(5 \mathrm{~kW})$ or the next generation $5-10 \mathrm{~kW}$ ion thruster under development by NASA. ${ }^{19}$

\section{Downselect}

Based on the established comparators, arcjets, Hall thrusters, and ion thrusters were chosen to proceed to second level of the study which includes integration and cost analyses. Power levels were chosen to be 5,10 , and $20 \mathrm{~kW}$ for the arcjet, Hall, and Ion thrusters, respectively since they all provide about $0.5 \mathrm{~N}$ of thrust at these power levels, and thus can all save about 45 MT of chemical reboost fuel. The other systems were not chosen, in some cases due to their immaturity and high power level requirements to provide notable chemical reboost fuel reduction (VASIMR, MPD, and PIT). The MET system was also considered too immature and required large amounts of fuel. No advantages were shown by the NH3 arcjet.

\section{Total Reboost System Mass}

The total reboost system mass is defined here to be the complete ISS integrated, wet EP 
system along with the required chemical fuel. Estimates of the EP subsystem masses as well as the added power generation subsystems (if needed) can be easily made. However, estimates of the mass required to integrate the EP system to ISS must be defined by more detailed analyses. Issues such as shuttle launch, ISS attachment and minimizing plume impacts can drive the integration mass to notable levels. Early estimates of the Hall and arcjet systems have shown this mass to be substantial (roughly 5500 and $3500 \mathrm{~kg}$, respectively). The Hall system integration mass was greater than the arcjet since a US side of the station attachment point was assumed (as opposed to the Russian side) and extendable booms were needed to place the thrusters beyond most space station components to avoid potential exhaust sputtering impacts. The Hall system also needed a dedicated, continuous $10 \mathrm{~kW}$ power system.

Figure 10 shows the estimated mass breakdown of the $5 \mathrm{~kW}$ arcjet and $10 \mathrm{~kW}$ Hall systems. Note that the chemical reboost fuel required is similar for each (about $20 \mathrm{MT}$ ) since both provide about $0.5 \mathrm{~N}$ of thrust. The main difference in the two systems is the larger electric propulsion fuel mass for the arcjet (due to its lower Isp) and the larger integration mass for the Hall as previously discussed. Ignoring volume constraints and assuming the shuttle system can launch about $16,000 \mathrm{~kg}$ of payload, the Hall and arcjet options will require two and three shuttle launches, respectively, to deliver the EP system over the ten year mission.

\section{Summary}

With the advent of operational electric propulsion technologies a two-phase study was conducted to evaluate the advantages of electric propulsion for the space station reboost mission. A code was developed using JSC data that modeled reboost of space station with various EP systems at various power levels. A major portion of reboost of ISS can be made using EP systems with $0.5 \mathrm{~N}$ of continuous thrust. $1.0 \mathrm{~N}$ of EP thrust can provide almost the entire reboost mission. Unfortunately, the requirement for ISS to descend to low altitudes (high drag conditions) to pick up Soyuz vehicles during solar max conditions would require EP thrust levels $>1.5 \mathrm{~N}$, necessitating large power levels for very short times during the mission.
Three electric propulsion systems were chosen for the second phase investigation: $\mathrm{N}_{2} \mathrm{H}_{4}$ arcjets, xenon Hall, and xenon ion thrusters. They were chosen for their chemical reboost fuel reduction (over 50\%) at reasonable power levels ( 5 to $20 \mathrm{~kW}$ ) and their maturity.

\section{References}

1. Greco, R.W., et al, Development of a Biowaste Resistojet Propulsion System Propellant Management and Control Subsystem, AIAA 72-0440, April, 1972.

2. Pugmire, T.K., et al, A 10,000 Hour Life Multipropellant Engine for Space Station Applications, AIAA 86-1403, June, 1986.

3. Tacina, R.R., Conceptual Design and Integration of a Space Station Resistojet Propulsion Assembly, AIAA 87-1860, June 1987.

4. Schmidt, G., Sensitivity of Propulsion System Selection to Space Station Freedom Performance Requirements, AIAA 892835, July, 1989.

5. Oleson S.R., Sankovic, J., Benefits of Low-Power Electrothermal Propulsion, 1996 JANNAF Interagency Propulsion Meeting ,Albuquerque, New Mexico, Dec. 9-13, 1996

6. Oleson, S.R., Hamley, J., Sankovic, J.M., Sample Mission Applications of Capacitor Powered Hall Thrusters, 33nd Joint Propulsion Conference, July, 1997, AIAA97-2785.

7. Lichon, P., Sankovic, J., Development and Demonstration of a 600 Second Mission Average Arcjet, IEPC-93-087, Sept. 1993.

8. Vaughan, C.E., Cassady, R.J., Fisher, J.R., The Design, Fabrication, and Test of a $26 \mathrm{~kW}$ Arcjet and Power Conditioning Unit, IEPC-93-048, Sept. 1993.

9. Sankovic, J.M., et al, Hydrogen Arcjet Technology, IEPC-91-018, Oct. 1991.

10. Micci, M.M., Low-Power Solid-State Microwave Thruster Systems, Proceedings of the3rd International Conference on Spacecraft Propulsion, pp203-209, Oct. 2000.

11. Sovey, J., et al, Development of an Ion Thruster and Power Processor for New Millennium's Deep Space 1 Mission, NASA TM-113129 AIAA-97-2778, Dec. 1997.

12. Sankovic, J.M., Caveny, L.H., Lynn, P.R., The BMDO Hall Electric Thruster Technology (RHETT) Program: From Laboratory to Orbit, AIAA 97-2917. 
13. Oleson, S.R., Advanced Hall Electric Propulsion for Future In-Space Transportation, $\quad 3^{\text {rd }} \quad$ International Conference on Spacecraft Propulsion, Cannes, France, Oct., 2000.

14. Stuckey, P., et al, SPT-140 High Performance Hall System (HPHS) Development, AIAA-98-4041,

15. Myers, R.M., "Electromagnetic Propulsion for Spacecraft", AIAA 93-1086, Aerospace Design Conference, Feb. 16-19, 1993, Irvine CA.

16. Dailey, C.L., Lovberg, R.H., "The PIT MkV Pulsed Inductive Thruster", Report to NASA Glenn Research Center, Dec. 1999, TRW Space and Technology Group, Los Angeles, CA.

17. F. R. Chang Díaz, Research Status of The Variable Specific Impulse Magnetoplasma Rocket", Proceedings of Open Systems 98, American Nuclear Society,

18. Mason, L., Jankovsky, R., Manzella, D. 1000 Hours of Testing on a $10 \mathrm{~kW}$ Hall Thruster, AIAA-2001-3773, July 2001.

19. Patterson, M. et al, Development Status of a 5-kW Class Ion Engine, AIAA-20013489, July 2001. 
Table 1. Electric Propulsion Options

\begin{tabular}{|c|c|c|c|c|c|c|c|c|c|c|}
\hline TRL Level & $\begin{array}{l}\text { EP System } \\
\text { Type }\end{array}$ & Isp & $\begin{array}{l}\text { Overall } \\
\text { Efficiency }\end{array}$ & \begin{tabular}{|l|} 
Nominal \\
Thruster \\
Power \\
Level - \\
into \\
PPU \\
(kW)
\end{tabular} & $\begin{array}{l}\text { Engine } \\
\text { Thrust } \\
\text { (N) }\end{array}$ & $\begin{array}{l}\text { Thruster } \\
\text { Life (fuel } \\
\text { through- } \\
\text { put) (kg) }\end{array}$ & $\begin{array}{l}\text { Thruster } \\
\text { life at } \\
\text { nominal } \\
\text { pwr } \\
\text { rating } \\
\text { (hrs) }\end{array}$ & \begin{tabular}{|l} 
Per \\
Thruster \\
Mass
\end{tabular} & $\begin{array}{l}\text { PPU } \\
\text { Mass }\end{array}$ & $\begin{array}{l}\text { Propellant } \\
\text { Tankage } \\
\text { Fraction }\end{array}$ \\
\hline 7 & $\mathrm{CO} 2 \mathrm{RJ}$ & 119 & 0.49 & 0.12 & 0.1 & 3131 & 10000 & 2 & 4 & 0 \\
\hline 2 & MET & 460 & 0.44 & 10 & 1.93 & $?$ & ? & 10 & 10 & 0.07 \\
\hline 9 & $\begin{array}{l}\text { N2H44 } \\
\text { arcjet }\end{array}$ & 600 & 0.32 & 3 & 0.27 & 299 & 1800 & 2.3 & 6.1 & 0.07 \\
\hline 7 & NH3 Arcjet & 800 & 0.27 & 30 & 2.06 & 1420 & 1500 & 6.7 & 2.1 & 0.07 \\
\hline 8 & Hall & 1770 & 0.52 & 5 & 0.30 & 497 & 8000 & 11.3 & 9 & 0.14 \\
\hline 9 & $\begin{array}{c}\text { NSTAR } \\
\text { Ion }\end{array}$ & 3160 & 0.60 & 3 & 0.10 & 159 & 14000 & 13.8 & 9.1 & 0.14 \\
\hline 2 & VASIMR & 5400 & 0.5 & 10 & 0.19 & $?$ & ? & 100 & 150 & 0.55 \\
\hline
\end{tabular}

Table 2. Summary of Results

\begin{tabular}{|c|c|c|c|c|c|c|}
\hline EP Technology & $\begin{array}{c}\text { Total } \\
\text { Power } \\
\text { Requird } \\
(\mathbf{k W})\end{array}$ & $\begin{array}{c}\text { Chemical } \\
\text { Propellant } \\
\text { Mass } \\
\text { Savings } \\
\text { (MT) } \\
\end{array}$ & $\begin{array}{c}\text { EP Fuel } \\
\text { Mass } \\
\text { (MT) } \\
\end{array}$ & $\begin{array}{c}\text { Required } \\
\text { EP and } \\
\text { Chem } \\
\text { Reboost } \\
\text { Fuel Mass } \\
\text { (MT) } \\
\end{array}$ & $\begin{array}{c}\begin{array}{c}\text { Number } \\
\text { of } \\
\text { Thrusters }\end{array} \\
\end{array}$ & $\begin{array}{c}\mathbf{E P} \Delta \mathbf{V} \\
(\mathbf{m} / \mathbf{s})\end{array}$ \\
\hline $\mathrm{CO2} \mathrm{RJ}$ & 0.1 & 5.4 & 27.1 & 86.9 & 9 & 67 \\
\hline MET & 2.5 & 41 & 30.5 & 54.7 & 80 & 293 \\
\hline MET & 5.0 & 59.5 & 45.0 & 50.7 & 118 & 433 \\
\hline N2H4 arcjet & 2.5 & 22.1 & 13.8 & 56.9 & 42 & 173 \\
\hline N2H4 arcjet & 5.0 & 43.2 & 25.1 & 47.1 & 86 & 315 \\
\hline N2H4 arcjet & 10.0 & 62.5 & 34.4 & 37.1 & 104 & 431 \\
\hline NH3 Arcjet & 5.0 & 26.4 & 11.9 & 50.7 & 9 & 199 \\
\hline NH3 Arcjet & 10.0 & 52.2 & 22.1 & 35.1 & 16 & 369 \\
\hline Hall & 5.0 & 24.2 & 5.1 & 46.1 & 11 & 187 \\
\hline Hall & 10.0 & 47 & 8.9 & 27.1 & 20 & 331 \\
\hline Hall & 15.0 & 55.6 & 11.1 & 20.7 & 24 & 412 \\
\hline Hall & 20.0 & 63.3 & 12.0 & 13.9 & 28 & 445 \\
\hline NSTAR Ion & 5.0 & 15.9 & 1.8 & 51.1 & 12 & 122 \\
\hline NSTAR Ion & 10.0 & 32.3 & 3.7 & 36.6 & 24 & 242 \\
\hline NSTAR Ion & 15.0 & 46.8 & 5.1 & 23.5 & 36 & 338 \\
\hline NSTAR Ion & 30.0 & 61.6 & 6.5 & 10.1 & 48 & 431 \\
\hline VASIMR & 5.0 & 4.5 & 0.6 & 61.3 & 2 & 63 \\
\hline VASIMR & 10.0 & 14.1 & 1.1 & 52.2 & 4 & 125 \\
\hline VASIMR & 20.0 & 31.8 & 2.1 & 35.5 & 7 & 237 \\
\hline VASIMR & 30.0 & 42.1 & 2.8 & 25.9 & 10 & 317 \\
\hline
\end{tabular}




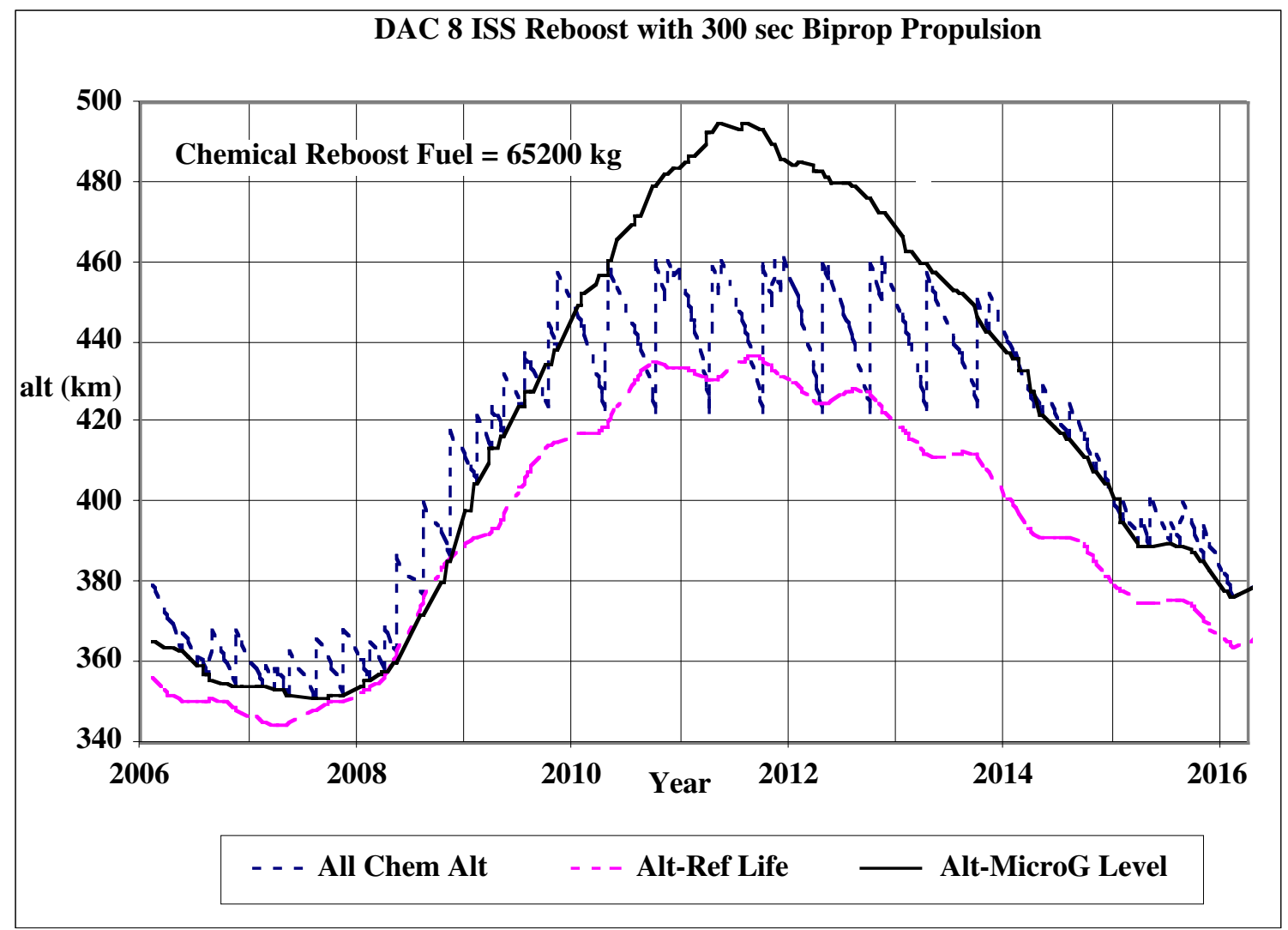

Figure 1. DAC 8 Reboost Strategy

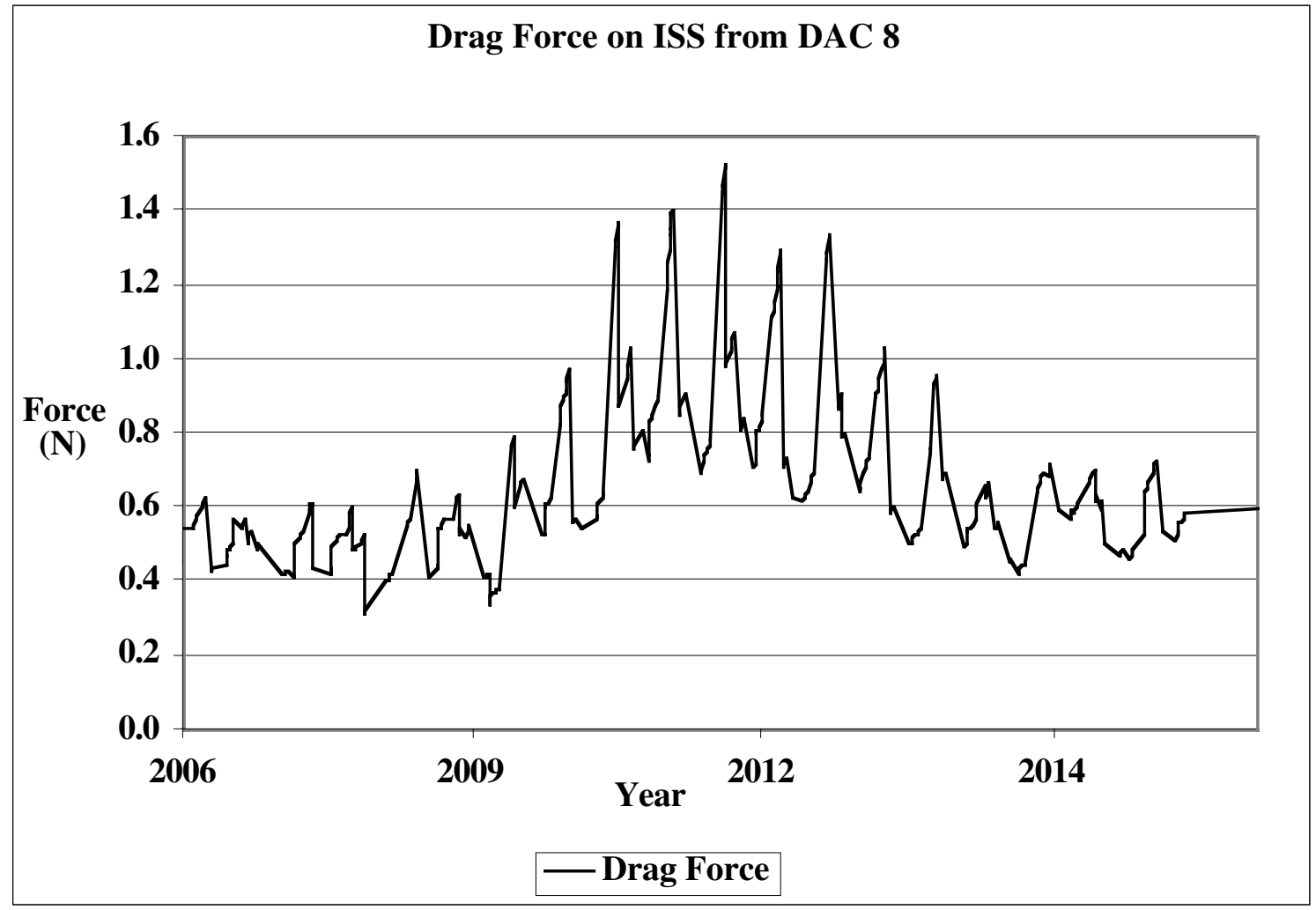

Figure 2. Drag Force on ISS 


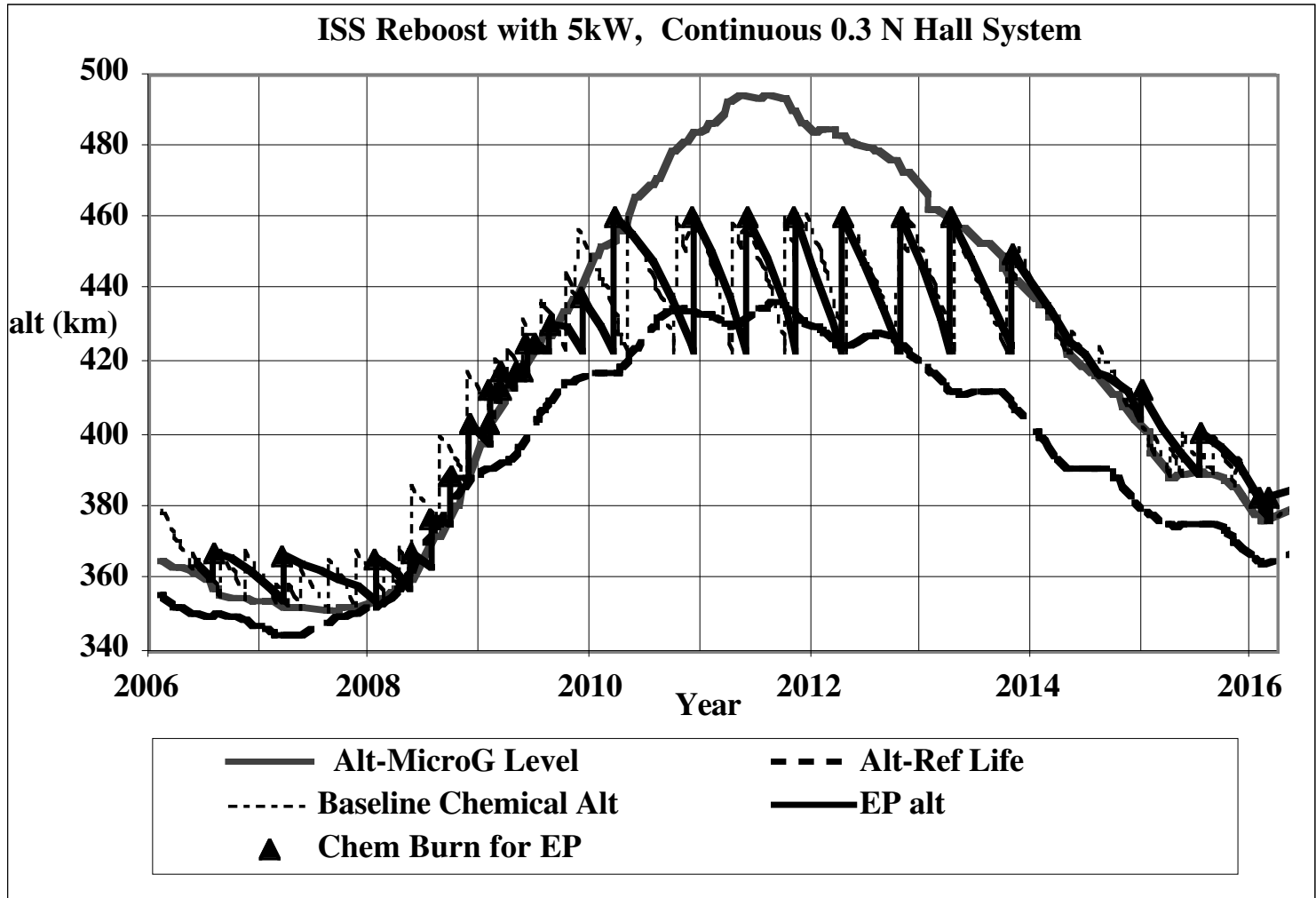

Figure 3. Parachute Strategy Example

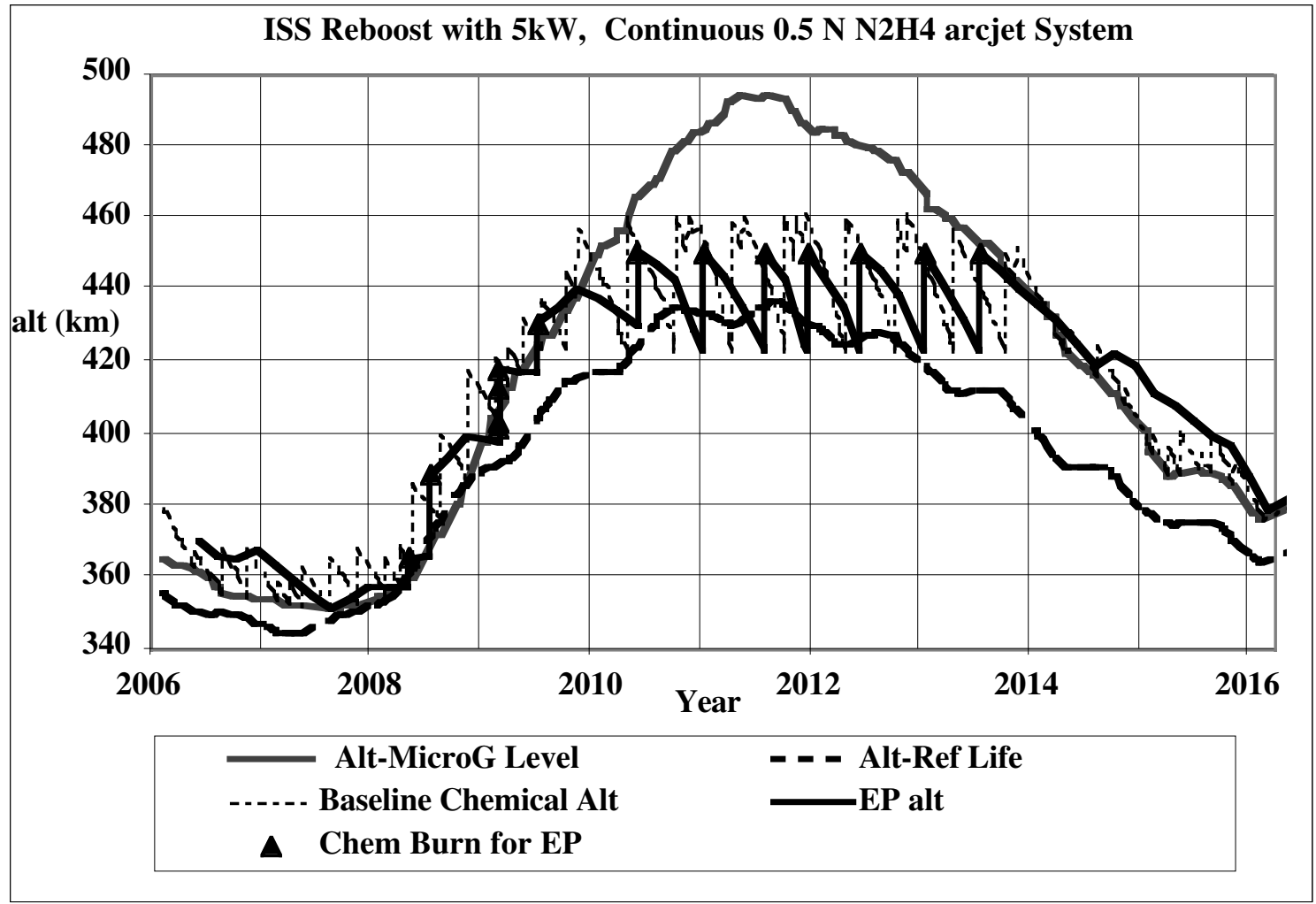

Figure 4. Partial Primary Strategy Example 


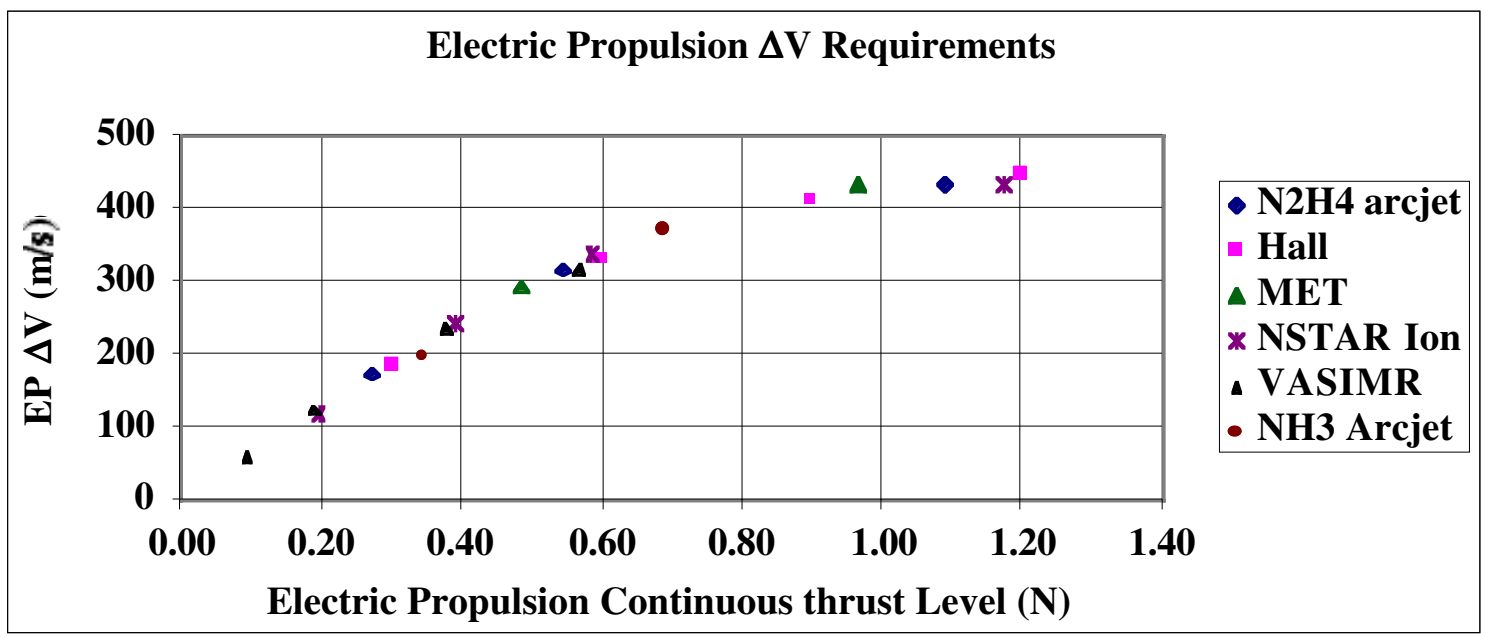

Figure 5. EP $\Delta V$ Requirements

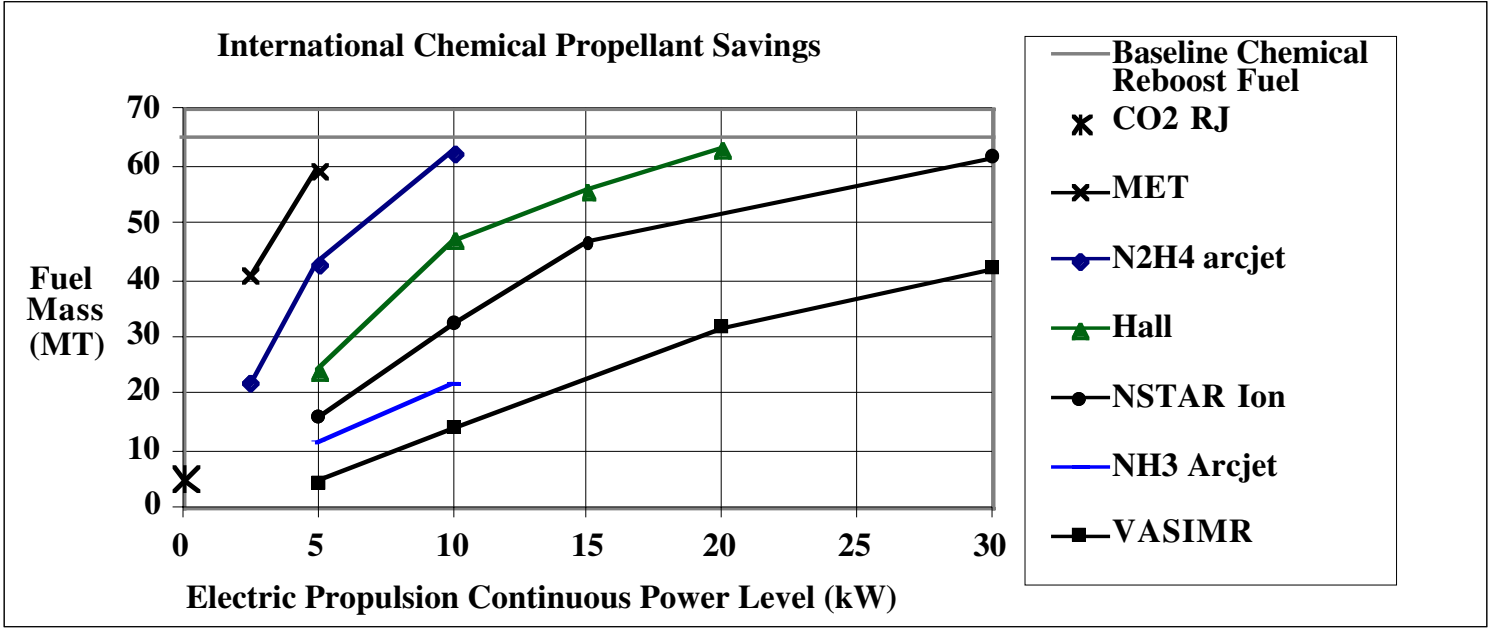

Figure 6. Chemical Propellant Savings

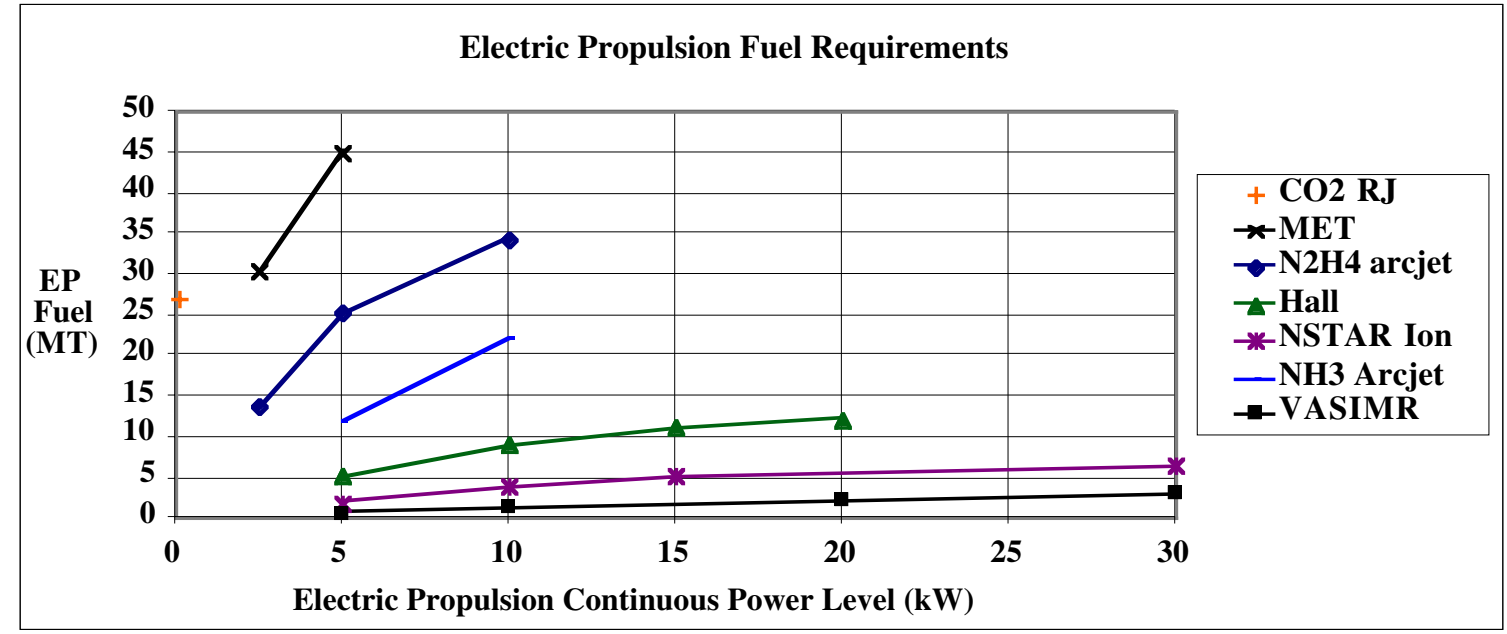

Figure 7. EP Fuel Requirements 


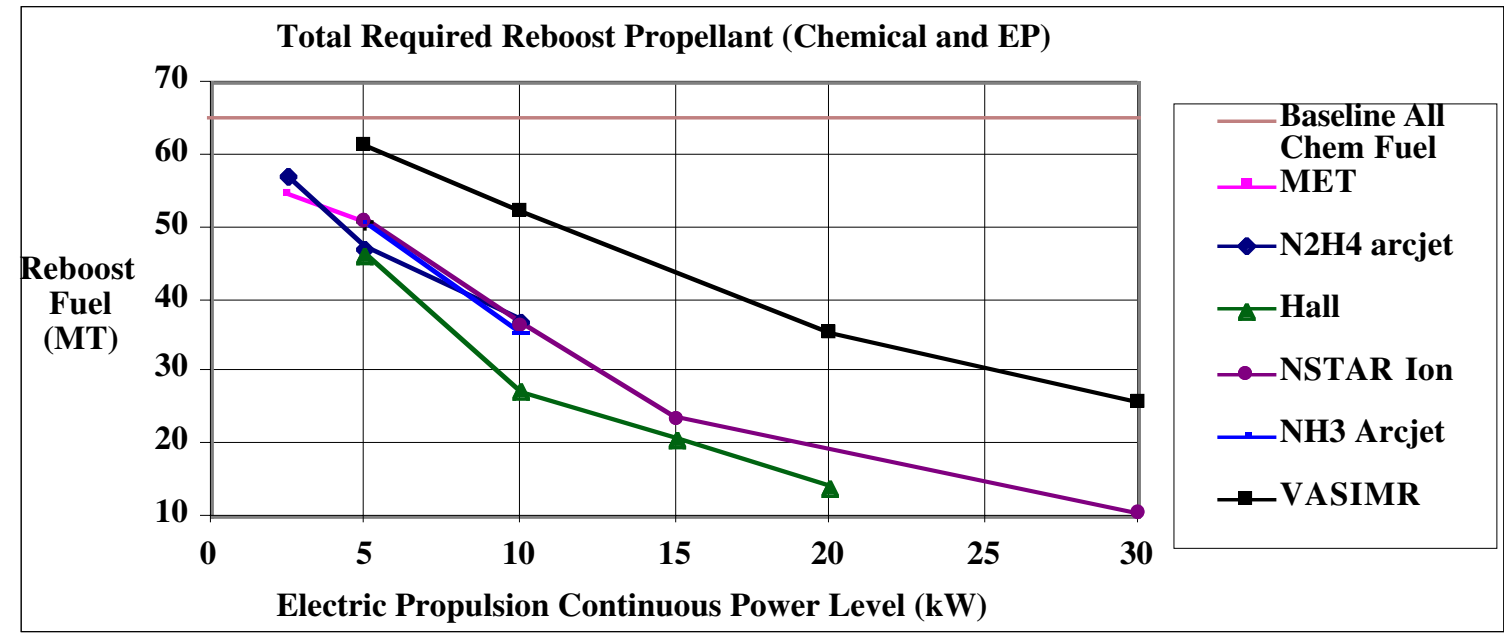

Figure 8. Total Reboost Propellant

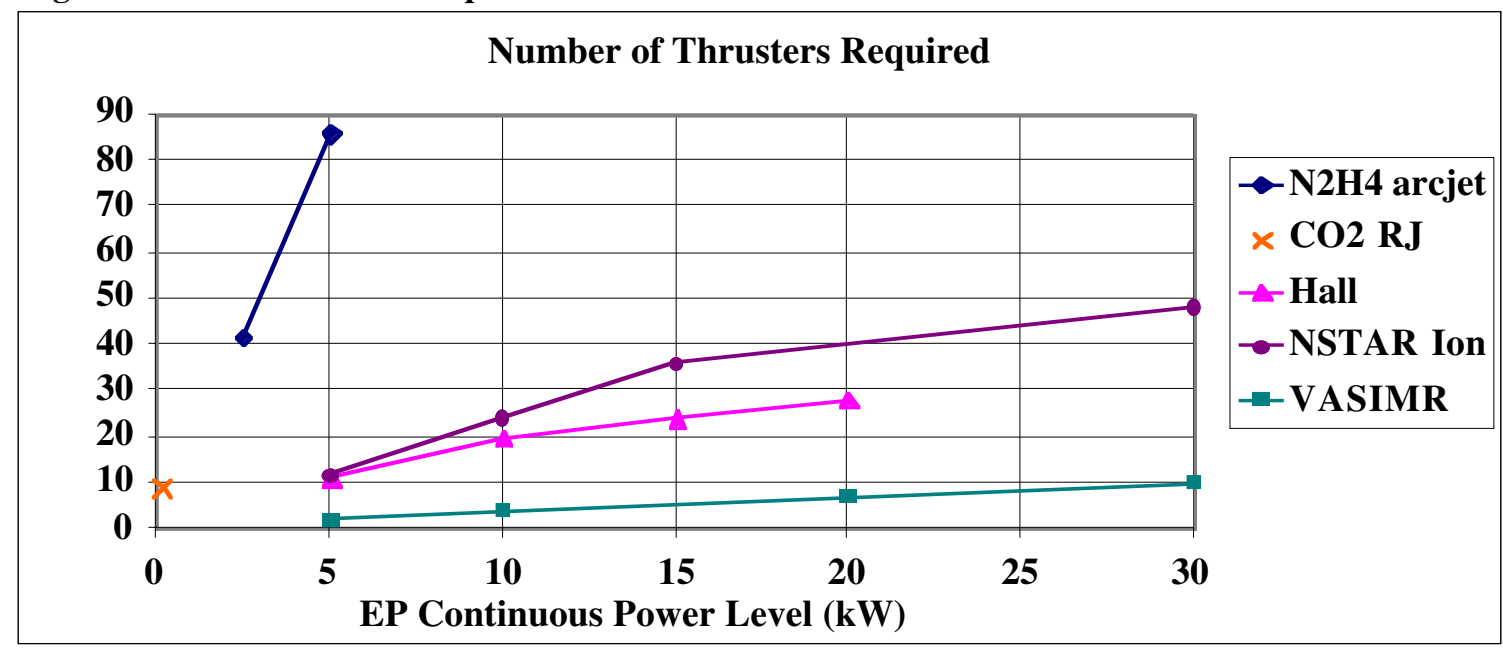

Figure 9. Number of EP Thrusters

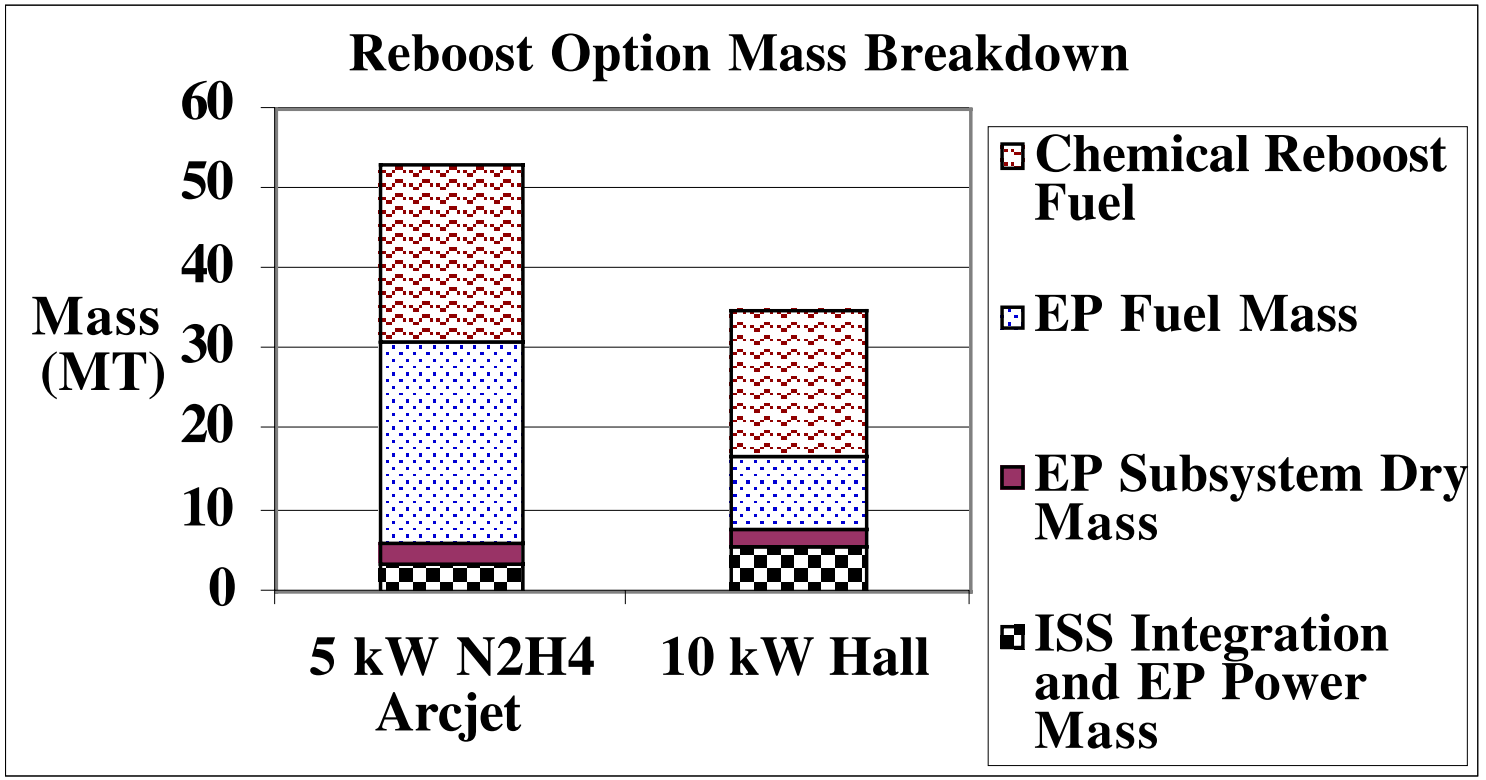

Figure 10. Integrated Mass Breakdown 


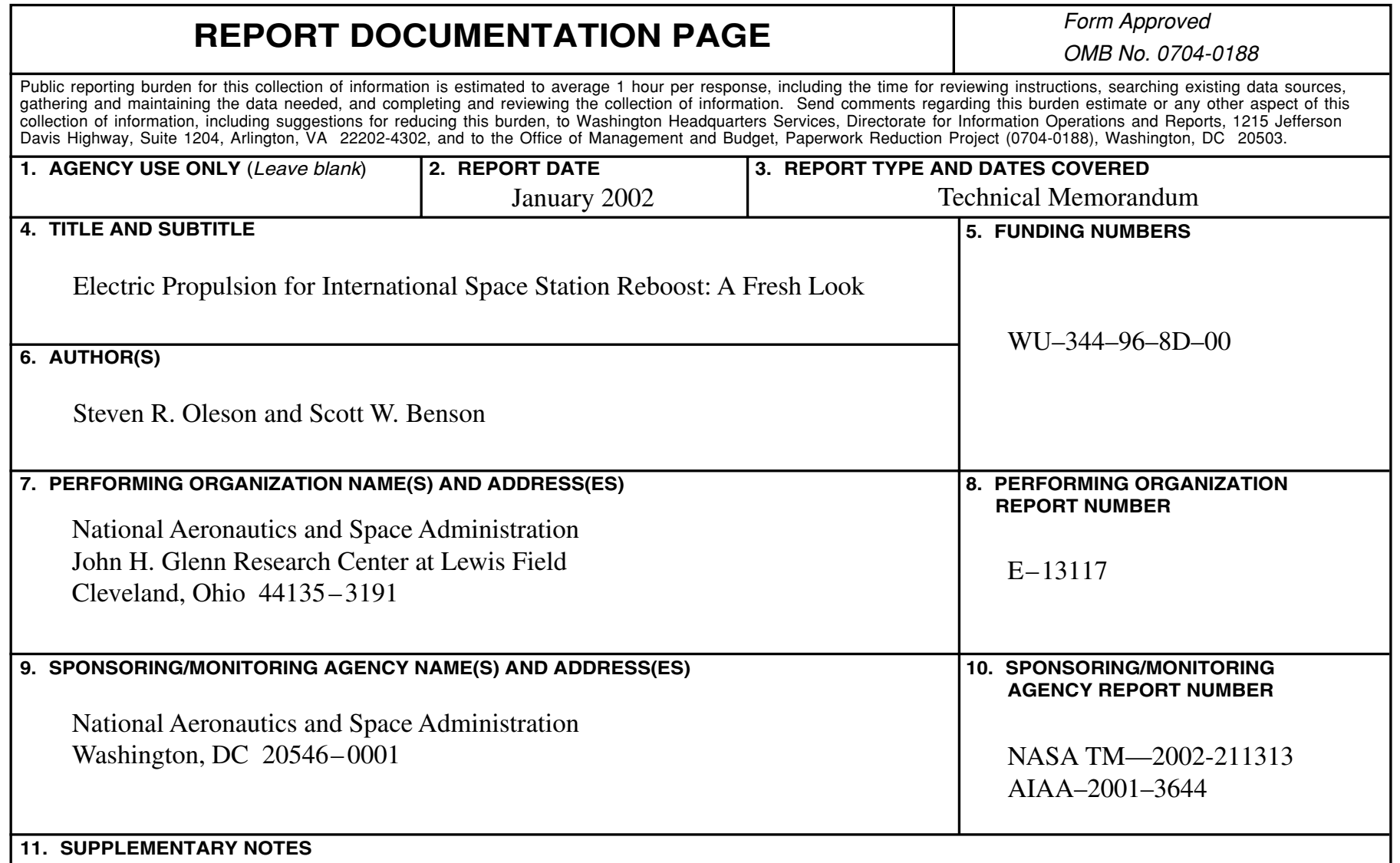

Prepared for the 37th Joint Propulsion Conference and Exhibit cosponsored by the AIAA, SAE, AIChE, and ASME, Salt Lake City, Utah, July 8-11, 2001. Responsible person, Steven R. Oleson, organization code 6910, 216-977-7426.

12a. DISTRIBUTION/AVAILABILITY STATEMENT 12b. DISTRIBUTION CODE

Unclassified - Unlimited

Subject Categories: 13, 15, 18, 20 and 28

Distribution: Nonstandard

Available electronically at http://gltrs.grc.nasa.gov/GLTRS

This publication is available from the NASA Center for AeroSpace Information, 301-621-0390.

13. ABSTRACT (Maximum 200 words)

Electric propulsion has recently been revisited for reboost of space station due to its high fuel efficiency. This paper focuses upon the propulsion system and orbit analysis trades undertaken at the beginning of a study to show the relative performance of potential electric propulsion system. A code was developed to analyze continuous low thrust reboost of space station with various electric propulsion systems at various power levels. Analysis showed that a major portion of reboost of space station can be made using electric propulsion systems with $0.5 \mathrm{~N}$ of continuous thrust. $1.0 \mathrm{~N}$ of EP thrust can provide almost the entire reboost mission. Three electric propulsion systems at various total power levels were chosen for further investigation: $\mathrm{N}_{2} \mathrm{H}_{4}$ arcjets at $5 \mathrm{~kW}$, xenon Hall at $10 \mathrm{~kW}$, and xenon ion thrusters at $20 \mathrm{~kW}$. They were chosen for their ability to reduce the internationally launched chemical reboost fuel by 50 percent or more.

\begin{tabular}{|c|c|c|c|}
\hline \multicolumn{2}{|l|}{ 14. SUBJECT TERMS } & & \begin{tabular}{|c|} 
15. NUMBER OF PAGES \\
19 \\
16. PRICE CODE
\end{tabular} \\
\hline NSN 7540-01-280-5500 & & & $\begin{array}{l}\text { andard Form } 298 \text { (Rev. 2-89) } \\
\text { scribed by ANSI Std. Z39-18 } \\
8-102\end{array}$ \\
\hline
\end{tabular}

